\title{
MOBILE AUTONOMOUS ROBOTS - A NEW TYPE OF CITY PUBLIC TRANSPORT
}

\author{
Vasili Shut $^{1}$, Valery Kasyanik ${ }^{2}$ \\ ${ }^{I}$ Brest State Technical University, Brest, Belarus,st. Moskovskaja, 267 \\ Ph.: +375295264295. E-mail: lucking@mail.ru \\ ${ }^{2}$ Brest State Technical University, Brest, Belarus, st. Moskovskaja 267 \\ Ph.:+375295274539.E-mail: vvkasyanik@bstu.by
}

\begin{abstract}
In the article the problem of modern cities - transport jams - is taken up. We propose several variants of solution and one of the main - the use of autonomous mobile robots as public transport. This is caused by active development of robotics. The article contains the review of the latest achievements of this perspective sphere and technical characteristic of two mobile robots for providing effectiveness of traffic. Functioning of robots takes place in confined environment with distinct infrastructure.
\end{abstract}

Keywords: robot, intellectual transport system, jam, city public transport, passenger traffic

\section{Introduction}

In system of road transport in which about $2 / 3$ all volumes of transport service are carried out, in this or that form works up to $8-10 \%$ of able-bodied people. In the subsystem of traffic system of road transport, each person, on the average, daily is about one hour, i.e. to $7 \%$ of the active time. Thus, road transport and traffic control entering into it are one of the most important life support systems of modern society. Development of transport infrastructure, including street road network development, development of new means of transport and management of it is an actual problem of modern society.

In these conditions automated control systems for movement of transport and foot streams in the cities constantly develop. The tendency of automatic control traffic systems can be considered in two directions.

The first direction - improvement of technical providing control systems by transport at the expense of development: electronic computing means, equipments of data transmission, widespread introduction of radio communication in a link "centre periphery" including channels of cellular communication, introduction of more perfect means of information display, expansion of transport detectors, building of intellectual opportunities and road controllers.

The second direction - strengthening of carried-out functions by the transport system providing improvement of service quality for passengers, and also development of new types of public transport.

Growth of load on the main highways of a street road network (SRN) of the cities leads to steady decrease of the speed of movement of transport streams and to formation of traffic block. Under traffic conditions close to a traffic block, the turn of vehicles cannot go in on a stage between the next intersections that lead to violation of an operating mode of the traffic light system of the previous intersection. Such situation extending on some intersections, received the name of a network jam or network [1-2] saturation.

The network jam against spasmodic growth of park of cars even more often comes in SRN of the large cities. Besides automobile transport (AT) the second consumer of an SRN resource is the city public transport (CPT) which share in passenger traffic is $60 \%$ (earlier this figure was $90 \%$ ).

It should be noted that CPT uses the SRN resource more effectively. On the average in the bus, a trolleybus, a tram 150 people, while in the car only 1,5 persons [3] go.

To avoid in the future the collapse of transport system and to support its functioning at optimum possible level it is necessary to carry out cardinal reorganization of all transport complex including SRN, management of transport streams, development of new types of CPT.

If the first position within historically developed city building hardly gives in to reorganization, the second and the third are quite possible. So use of adaptive management by transport streams in SRN allows increasing capacity of a network [4-5] on 20-30\%.

Further it will be necessary to limit unreasonable growth of transport streams from cars to a way of input of quotas of a trip. Everything that is above this quota should be paid. In economy it is known that free of charge provided resource injuriously is taken away. The share of CPT in transport streams plying in SRN as a result will increase at the general reduction of number of transport units. 
Given above a measure are necessary, but are insufficient. Essential expansion of capacity SRN excluding collapse, is possible on a way of essential revision of principles of management of transport streams on the basis of modern achievements in the field of informatics, telecommunication systems, collective behaviour of automobile, a robotics.

All in large quantities and in a variety of qualities the robots become our reality: in art, life, production, etc. There are robot violinists [6], robot cooks [7], robot nannies, robot engineers, robot firemen [8], security guards and others.

Robots are indispensable in many industries. For example, the robot welders are commonly used in automobile production. There are robots engaged in painting. In the electronics industry robots are used for soldering microscopic wires, placement of integrated circuits on circuit boards in monitoring and diagnosis of completed devices, and more. Robots are used in traffic management of vehicles [9]. These specialized robots make the same high-precision work every day. For a human, such work is boring and tedious - the monotony leads to fatigue, which causes errors. Production errors are decreasing the labour productivity. This in turn leads to increased production costs.

Robots are ideal for monotonous work. The speed of their work is higher; they are cheaper than workers because people are inclined to fatigue. This is one of the reasons for the low prices of products.

We propose another type of robots - pedestrian, working at pedestrian crossings and performing a set of cyclic operations. In the real work one more type of collectives of robots - transport, working in $\mathrm{SRN}$ of the city and cyclic operations carrying out a set is offered.

\section{Robots in Transport System}

The last twenty years the idea of management of motor transport without participation of the driver actively develops. One of the directions of development of intellectual transport is development of vehicles for intercity transportation of passengers. A distinctive feature of such vehicles is interaction of the passenger with a vehicle and absence of the operating person. Further development in this direction will allow creating intellectual information system of movement of vehicles.

The last 20 years the idea of creation of transport without participation of the driver (autonomous transport) actively develops. In view of what the question of movement regulation of pilot fewer vehicles is actually. One of the directions of intellectual transport development is integration autonomous vehicles in intercity transportation of passengers. Distinctive feature of such vehicles is interaction of the passenger with the vehicle and lack of the operating person. Further development in this direction will allow creating intellectual information system of vehicles movement.

The project "The robotics pipeline system "Crosswalk" [10] is known. This system carries out shuttle transportations on a crosswalk of pedestrians through the highway with heavy motor transportation traffic. The basis of system is made of the mobile robot.

Electric vehicle runs along a pedestrian crossing non-constantly. Transport detectors measure the intensity of traffic flow and in a case of falling below set value, the electric car moves to left side (Fig. 1). In this case, the crosswalk is used in the traditional way.

The electric car stays in parking place at night, and, as specified above, during the low intensity of traffic flows. At this time he connects to the charging station.

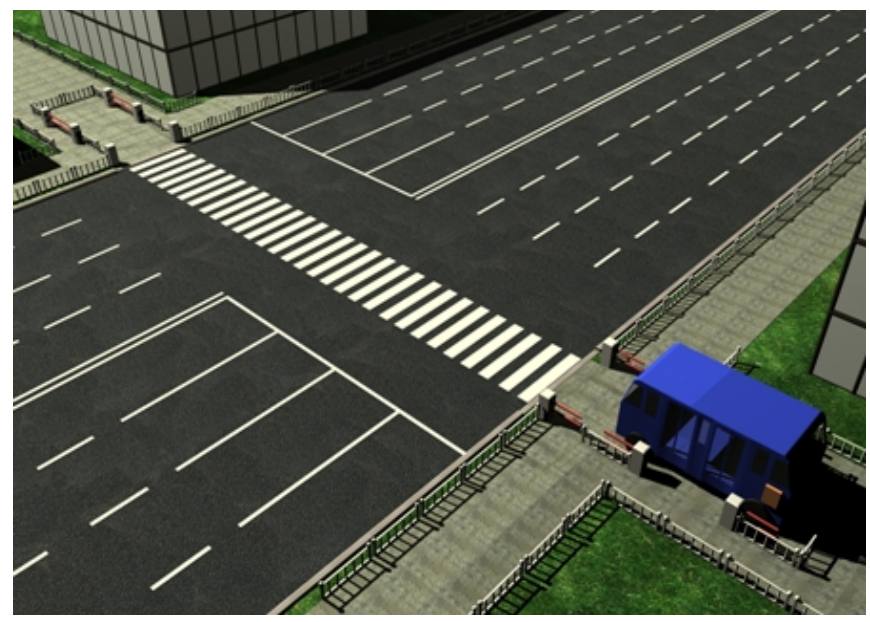

Figure 1. The crosswalk system electric motor car at the moment of loading 
It is the first type of the robots working in SRN of the city. In this work one more type of the robots, which are working also in SRN of the city and carrying out a set of cyclic operations of transportation of passengers, only any more across the highway, and along is offered and investigated. The main objective of consideration is development of model of the automated system of transportation with use of artificial intelligence.

\section{Intellectual Transport Systems}

Intellectual transport systems (ITS) - a class of the transport systems providing steady, effective, economic and safe functioning of transport at the expense of giving to active elements of transport system of properties of adaptive (intellectual) behaviour. Two most important aspects of intellectual transport system (ITS) are ATMS (Advanced Traffic Management Systems - the advanced control system of movement) and ATIS (Advanced Traffic Information Systems - the advanced information system) [11].

ITS - a complex of the interconnected automated systems solving problems of management of traffic, monitoring and management of work of all means of transport (individual, public, cargo), and the enterprises on the organization of transport service in the region territory.

The automated transport systems, for which the short English-speaking term people-mover is thought up, appeared in 1967 in the form of the trains serving visitors of the World Fair in Montreal.

Driverless car (the car without the driver or an independent vehicle) is a vehicle equipped with system of the autopilot, and capable to move from one point to another without the aid of the operator. EC EUREKA Prometheus Project, 2getthere from the Netherlands, the research company ARGO in Italy, management of the perspective research DARPA programs in the USA, and Google driverless car are engaged in development of programs for autonomous cars.

The history of independent vehicles begins from 1977 with laboratory of mechanical engineering of Tsukuba in Japan. In the 1980th years the video operated robot van of the Mercedes-Benz company developed by Ernst Dikmanns and his team at the Bundeswehr University in Munich, reached $100 \mathrm{~km} / \mathrm{h}$ on streets without movement. Subsequently, the European commission began financing with 800 million euros the EUREKA Prometheus Project on independent vehicles (1987-1995) [12].

Also in the 1980th years "The program independent land vehicles" (Autonomous Land Vehicle ALV), financed by Management of the perspective research DARPA programs of the United States, achieved the first demonstration on the road of an independent vehicle with use of a laser radar.

In 1994 two VaMP and Vita-2 cars robots from Daimler-Benz and Ernst Dikmanns from UniBwM overcame more than one thousand kilometres on the Parisian three-lane highway with usual dense movement at a speed of $130 \mathrm{~km} / \mathrm{h}$, though they were semi-autonomous with human intervention. They showed independent driving in free lanes, driving in a column, the left and right transference on strips with an independent pass ahead of other cars.

In 1995, converted independent Mercedes-Benz of an S-class Dikmanns made 1600 kilometres travel from Munich to Copenhagen and back, using faltering computer supervision and the so-called transputer - that is the computer working in real time. The robot reached speeds more than $175 \mathrm{~km} / \mathrm{h}$ on the German highway (with the 95th \% independent driving).

In 1995 the Navlab project (Carnegie Mellon's university) reached independent driving for 98.2\%, having overcome $5000 \mathrm{~km}$. This car, however, was semiautonomous by the nature: it used neural networks to operate a wheel, but a throttle and a brake were operated by person.

From 1996 till 2001 Alberto Brogkhi from university of Parma began the SLANG project with the purpose of riding along marking of the highway. The way in $2000 \mathrm{~km}$ became the culmination of the project on highways of northern Italy with average speed of $90 \mathrm{~km} / \mathrm{h} .94 \%$ of time the car was completely in an automatic mode. The vehicle had only two black-and-white cheap video cameras on a board and used three-dimensional algorithms of supervision for environment recognition.

In 2008 of General Motors declared that they will start to test independent cars to 2015, that to 2018 they could be on the road.

From the executed consideration it is possible to draw the following conclusions. Works in the field of creation of independent vehicles will constantly accrue. In this direction it is possible to allocate four approaches:

- completely independent vehicles;

- various connections to infrastructure (either all area, or certain streets) to create the independent closed system;

- systems of "help", which by development on reduce requirements to the person driver (for example, updating of system of automatic control of speed or cruise control);

- creation of road trains. 
What is the development of system of road trains? To use road space better, vehicles are collected in columns similar to a train where the driver (either human or automatic) of the first vehicle makes all decisions for all column. All other vehicles simply follow the leader - the first vehicle.

For completely autonomous driving it is necessary, that the car drives itself to the set purpose, using not changed infrastructure. The ultimate goal in safe moving in any situation nevertheless isn't reached yet. Therefore it is possible to draw a conclusion that at this stage of development it is necessary to use as much as possible possibilities of robots to perform intended work well specially in limited environment or in the environment with not changed infrastructure.

To such systems belongs the automated transport system Crystal Mover from "Mitsubishi" which has many interesting decisions and innovative development. Its cars in length of 11,84 m contain 103 passengers, and develop till $80 \mathrm{~km} / \mathrm{h}$ ! In a track they are kept by lateral rollers, and noise is cancelled with car tires. The driving gear is electric, a current moves through the current collector, like in the subway. This system works not only at the airports - Miami, Washington, Hong Kong, Singapore, Seoul, but also in the cities - Kobe, Tokyo, Hiroshima, Kanazava, Singapore.

Also to this class of the systems working in specially prepared, limited environment or in the environment with not changed infrastructure belongs automated transport system of mass conveyor transportation of passengers on the basis of mobile robots of development of the Brest state technical university (BrSTU). Intellectual transport system BrSTU is the complex system providing effective, economic, steady and safe functioning of transport at the expense of giving to elements of transport system of properties of adaptive, intellectual behaviour. The intellectual information transport system of mass conveyor transportation of passengers is the difficult complex intended for optimisation of transportation of passengers in city boundaries in an independent mode, i.e. without the driver. It is intended for transportation of passengers in Minsk. The high urgency of development consists in that in Minsk currently on routes of CPT there is lack of 500 drivers.

\section{Description of Transport Intellectual System BrSTU}

The model of representation of each element is defined by its function in transport system. The basis of system is represented by the following elements:

- intellectual stop;

- intellectual traffic light;

- the intellectual electric truck for transportation of passengers;

- electronic ticket;

- $\quad$ software of transport intellectual system;

- $\quad$ server center.

\subsection{Intellectual Stop}

The intellectual stop is intended for improvement of quality of service of passengers of public transport at the expense of installation of various means:

- the information display - provides to passengers at stops with operational and actual information;

- information about arrival time of transport;

- advertising information;

- $\quad$ providing passengers with tourist information on the city;

- call of the dispatcher and services of emergency reaction;

- $\quad$ video surveillance modules - are intended for control of offences, definition of degree of load of a stop.

Data on the current load at a stop, and also all calls of transport are transferred in the server centre for processing. Also data can be requested directly by the electric truck.

\subsection{Intellectual Traffic Light}

The intellectual traffic light includes the following modules:

- module of regulation of traffic

- $\quad$ video surveillance module 
Traffic is regulated so that to provide the minimum idle times of the electric truck in case of the increased load.

Data on the current load on a traffic light and about a condition of work are transferred in the server centre for processing. Also data can be requested by the electric truck.

\subsection{The Intellectual Electric Truck for Transportation of Passengers}

The intellectual electric truck is intended for improvement of quality of service of transported passengers by means of the following modules:

- the module of sale of tickets for passengers at which isn't present the electronic ticket manual purchase of the ticket in salon;

- the module of control of payment of journey for passengers at which is the electronic ticket;

- the video surveillance module behind salon for control of offences (counts up number of passengers in salon, defines the violators who have not paid for journey);

- the module of satellite navigation for control of location;

- the wireless module of interaction with other electric trucks for realization of a multi-agent approach between electric trucks;

- the wireless module of interaction with intellectual traffic lights (the electric truck can request from a traffic light providing conditions of the minimum delays on traffic lights in case of high load);

- button of an emergency call of the dispatcher.

Electric trucks exchange information about the current load of stops, number of transported passengers. It provides realization of a principle of the multi agent system, allowing minimizing a waiting time of passengers at stops.

The passenger can cause the electric truck at a stop by means of the terminal. The inquiry goes on the server centre which on the basis of these and other data selects the optimum electric truck and sends it inquiry.

The electric truck when receiving inquiry is obliged to stop at the specified stop and to take away passengers. In a case when the amount of passengers is more than empty seats in the electric truck, the inquiry in the centre on receiving one more electric truck is sent. ticket.

After landing the passenger should either get the ticket, or use previously the bought electronic

\subsection{Electronic Ticket}

The ticket is executed in the form of analogue of a plastic credit bank card; provides replenishment of money on the ticket account, and as their automatic removal at journey in the electric truck.

Software of intellectual system includes:

- information processing from video cameras;

- $\quad$ processing of navigation information;

- interaction protocols between electric trucks and intellectual traffic lights;

- collecting analytics and statistics and protocols of protection of information;

- electronic tickets;

- information displays and terminals.

\subsection{Server Centre}

The server centre represents complex control centre of transport intellectual system. It is presented by processing and data storage servers (economic and statistical information), realizing the following functional:

- information processing from video cameras at stops

- processing of requests from terminals at stops

- management of information displays

- information processing from video cameras in electric trucks

- information processing from intellectual traffic lights

- analysis of load of routes and choice of optimum algorithm of work. 


\section{Conclusions}

The project offered in the article "Mobile Autonomous robots - a new type of city public transport" discovers a new type of public transport and intends for increase of mobility and flexibility of transportation of passengers. The project has a large economic profit. As a result of working at the project we have considered two types of mobile robots that are intended for functioning in road network of a city. Their functioning takes place in confined environment with distinct infrastructure. Possible fortuitous departures from the described environment are included in a zone of robot's reaction. On the base of these robots the conception of new type of public transport is formed up.

This project is in the stage of the draft. At present computer modelling of the system in different modes of intensity of passenger traffics is carried out. In the future authors hope for joint working with such an authoritative in Belarus producer of tram and trolleybus machinery as Belkommunmash.

\section{References}

1. U. S. Department of Transportation Federal Highway Administration (FHWA). Retrieved June 20, 2012, from http://www.fhwa.dot.gov

2. Kapitanov, V. T. (1985). Management of transport streams in cities. V. T.Kapitanov, E. B. Khilazhev (Eds.). M.: Transport.

3. Mikhaylov, A. Yu. (2004). Current trends of design and reconstruction of street road networks. A. Yu. Mikhaylov, I. M. Golovnykh (Eds.). Novosibirsk: Science.

4. Anfilets, S., Shut, V. (2010). Evaluating the Effectiveness of the Adaptive Control System in Brest Region. In Proceedings of the International Congress of Heavy Vehicles, Road Trains and Urban Transport, 2010, (pp. 222-226). Minsk: BNTU.

5. Kasianik, V. V., Anfilets, S. V., Shuts, V. N. (2010). Application of Artificial Neural Networks for Forecasting of Characteristics of Transport Stream and Adaptive Regulation at Crossroads. In Proceedings of the International Conference on Neural Networks and Artificial Intelligence, 2010 (pp. 91-93). Brest: BSTU.

6. Toyota's Humanoid Robot Violinist. Retrieved 2009, from http://www.thinkartificial.org/robotics/toyotashumanoid-robot-violinist/

7. Robot - sushi. Retrieved 2009, from http://www.robotsushi.com

8. Lovin, J. (2007). We create the robot - an android the hands. Moscow: DMK-Press.

9. Golovko, V. A. (2010). Basis of artificial intelligence. V. A. Golovko, L. P. Matyushkov, V. N. Shut (Eds.). Brest: BrSTU.

10. Shut, V. N. (2011). The robotics Crosswalk pipeline system. Artificial Intelligence Journal, 3, 423-427.

11. Intellectual transport system. Retrieved 2011, from http://scipeople.ru/group/435/.

12. Group of companies (group of companies) "M2M telematics". Retrieved 2012, from http://m2m-t.ru/. 